\title{
INTERAÇÃO ENTRE HERBICIDAS NO CONTROLE DE SOJA RR VOLUNTÁRIA NA CULTURA DO MILHO
}

\section{CONTROL OF SOYBEAN RR VOLUNTARY IN CULTURE OF CORN WITH DIFFERENT DOSES AND MIXTURES OF HERBICIDES}

Lilian Lúcia Costa ${ }^{\mathrm{a}}$, Dieimisson Paulo Almeida ${ }^{\mathrm{b}}$, Paulo César Timossi ${ }^{\mathrm{c}}$, Thiago Camargo de Melo Santos ${ }^{\mathrm{a}}$, Felipe de Oliveira Bonifácio ${ }^{\mathrm{a}}$, Beatriz de Oliveira Borges $^{\text {a }}$

${ }^{\mathrm{a}}$ Departamento de Agronomia, Instituto Federal Goiano, Campus Morrinhos, Goiás, Brasil. ${ }^{\mathrm{b}}$ Pesquisador Agronômico, Instituto de Ciência e Tecnologia Comigo, Goiás, Brasil. ${ }^{\mathrm{c}}$ Departamento de Agronomia, Universidade Federal de Goiás, Regional Jataí,Campus Jatobá, Goiás, Brasil.

*Autor correspondente: lilian.costa@ifgoiano.edu.br.

\section{INFORMAÇÕES DO ARTIGO \\ Histórico do artigo:}

Recebido: 31 Janeiro 2019.

Aceito: 01 Julho 2019.

Publicado: 25 Agosto 2019

\section{Palavras-chave/Keywords:}

Atrazine/ Atrazine.

Glyphosate/ Glyphosate.

Plantas Daninhas/ Weeds.

Plantas Transgênicas/Transgenic Plants.

Seletividade/ Selectivity.

Direito Autoral: Este é um artigo de acesso aberto distribuído sob os termos da Licença Creative Commons, que permite uso, distribuição e reprodução irrestritos em qualquer meio, desde que o autor e a fonte originais sejam creditados.

\section{Citação deste artigo:}

COSTA, L. L.; ALMEIDA, D. P.; TIMOSSI, P. C.; SANTOS, T. C. M.; BONIFÁCIO, F. O.; BORGES, B.O. Interação entre herbicidas no controle de soja rr voluntária na cultura do milho.Revista Brasileira de Herbicidas, v. 18, n.2. 2019.

\begin{abstract}
RESUMO
A soja com a biotecnologia denominada Roundup Ready (RR) é tolerante aos efeitos letais dos herbicidas a base de glyphosate, então as opções tradicionais de dessecação não são suficientes para o manejo destas plantas. Objetivou-se avaliar a eficácia da interação de herbicidas no controle das plantas de soja voluntária RR e a seletividade na cultura do milho. O experimento foi conduzido em delineamento inteiramente casualizado, em casa de vegetação com plantas de soja (RR) e milho. Os tratamentos foram constituídos pela combinação dos herbicidas glyphosate e duas atrazine em diferentes doses. Os herbicidas foram aplicados em plântulas de soja no estádio fenológico V1, V2 e V3 e, em plântulas de milho no estádio V3. A mistura de glyphosate e atrazine proporcionou controle da soja voluntária RR nos três estádios avaliados e desenvolvimento do milho compatível com a testemunha Quando o objetivo for apenas o controle da soja voluntária RR dispensa-se a adição do glyphosate a atrazine. $\mathrm{O}$ uso da menor dose recomendada em bula dos produtos Proof $^{\mathbb{R}}$ e Primóleo ${ }^{\circledR}$ controlam eficientemente plantas de soja voluntária RR na cultura do milho.
\end{abstract}




\section{Introdução}

O cultivo de grãos, mais de uma vez ao ano, na mesma área, é realizado por poucos países, entretanto, a sucessão soja (Glycine max L. Merril) e milho (Zea mays L.) é um sistema produtivo explorado nos estados de Goiás, Mato Grosso do Sul, Mato Grosso e Paraná (ADEGAS et al. 2011). A semeadura do milho em segunda safra, após a colheita da soja, denominado também como milho "safrinha" é uma realidade no Brasil e ocupa áreas expressivas de produção (ARTUZI; CONTIERO, 2006; PETTER et al., 2015).

No método de produção usando a sucessão de culturas, os restos de grãos na lavoura são comuns após a colheita, devido a fatores naturais da planta como a deiscência das vagens naturalmente e durante o processo de colheita, dando origem a plantas voluntárias na cultura subsequente, também conhecida como plantas guaxas ou voluntárias (COSTA et al., 2014; MARCA et al., 2015; PETTER et al., 2015). Para se evitar interferência na cultura de interesse, uma prática eficiente é a utilização de herbicidas (DAN et al., 2011; GRIGOLLI et al., 2017). De acordo com Maciel et al. (2013) quando estas plantas voluntárias são originadas de materiais resistentes ao glyphosate, a complexidade no controle químico aumenta significativamente.

A soja com a biotecnologia denominada Roundup Ready (RR) é tolerante aos efeitos destrutivos e letais de herbicidas a base de glyphosate e mesmo após a sua aplicação elas continuam produzindo aminoácidos essenciais ao seu crescimento e desenvolvimento (BRADSHAW et al., 1997). Desta forma, as opções tradicionais de dessecação não são mais suficientes para o manejo destas plantas.

A combinação de herbicidas é uma opção para o controle de soja voluntária na cultura do milho, assim houve relato que o uso da associação de herbicidas, atrazine com o glyphosate, promove e intensifica o controle de plantas- daninhas de folha larga e da soja voluntária com custo reduzido (TREZZI et al., 2005). Entretanto, é importante salientar, tem-se a opção de aumentar a dose do herbicida atrazine para obter-se controle em pré-emergência das plantas-daninhas.

De acordo com Gazziero (2015), a mistura de produtos fitossanitários no tanque do pulverizador, já era uma prática usual por produtores de todas as regiões do Brasil, representando 97\% dos casos. Agora diante a da normatização de tal prática os engenheiros agrônomos terão que se respaldar em pesquisas científicas que comprovem a eficácia agronômica (BRASIL, 2017)

A decisão em utilizar a mistura de produtos fitossanitários no tanque do pulverizador pode ocasionar resultados inesperados como sinergismo, adição ou antagonismo devido às compatibilidades e/ou incompatibilidades físico-químicas, podendo melhorar o controle ou ocasionar perdas ou diminuição na eficiência da aplicação (QUEIROZ et al., 2008; PETTER et al., 2013; IKEDA, 2013).

Visto a importância do conhecimento sobre a eficácia do controle do alvo biológico, estudos prévios devem ser realizados a fim de evitar prejuízos na aplicação. Portanto, com este estudo propõe-se identificar a melhor combinação de doses e/ou misturas entre dois produtos comerciais com herbicida atrazine com um produto formulado com glyphosate, no controle das plantas de soja voluntária RR e a seletividade na cultura do milho e interações.

\section{Material e Métodos}

O experimento foi conduzido em casa de vegetação em delineamento inteiramente casualizado, com dez tratamentos (Tabela 1) e quatro repetições, com temperatura controlada de $26^{\circ} \mathrm{C}$ à $30^{\circ} \mathrm{C}$, utilizando-se a cultivar de soja M7739 IPRO, e de milho BM 3063 PRO 2.

Tabela 1. Tratamentos utilizados para avaliar o controle da soja voluntária e fitotoxidade em plantas de milho.

\begin{tabular}{|c|c|c|c|}
\hline Ingrediente ativo & Produto comercial (p.c) & Dose (p.c L ha ${ }^{-1}$ ) & Dose (e.a e i.a. $\mathrm{kg} \mathrm{ha}^{-1}$ ) \\
\hline Glyphosate + Atrazine & Roundup Transorb + Primóleo & $2,0+6,0$ & $0,960+2,4$ \\
\hline Glyphosate + Atrazine & Roundup Transorb + Primóleo & $2,0+3,0$ & $0,960+1,2$ \\
\hline Glyphosate + Atrazine & Roundup Transorb + Proof & $2,0+4,8$ & $0,960+2,4$ \\
\hline Glyphosate + Atrazine & Roundup Transorb + Proof & $2,0+2,4$ & $0,960+1,2$ \\
\hline Atrazine & Primóleo & 6,0 & 2,4 \\
\hline Atrazine & Primóleo & 3,0 & 1,2 \\
\hline Atrazine & Proof & 4,8 & 2,4 \\
\hline Atrazine & Proof & 2,4 & 1,2 \\
\hline Glyphosate & Roundup Transorb & 2,0 & 0,960 \\
\hline Testemunha & -------- & -------- & -------- \\
\hline
\end{tabular}


Os tratamentos foram constituídos pela combinação dos herbicidas glyphosate (Roundup Transorb, 480 g e.a. $\mathrm{L}^{-1}$, SL, Monsanto) com dois produtos comerciais formulados com a atrazine (Primóleo, SC 400 g i.a L ${ }^{-1}$, SC, Syngenta) e (Proof ,500 g i.a L ${ }^{-1}, \mathrm{SC}$ ) nas doses descritas na Tabela 1.

Cada unidade experimental foi constituída por um vaso plástico com capacidade de $0,002 \mathrm{~m}^{3}$ para as plantas de soja e de $0,007 \mathrm{~m}^{3}$ para milho. O substrato em que estas espécies vegetais foram conduzidas foi composto por uma mistura de Latossolo Vermelho distrófico típico (SANTOS et al., 2014), de textura argilosa, esterco bovino e areia grossa lavada, respectivamente, na proporção 3:1:1, além de adubação química, , cada vaso com plantas de soja recebeu adubação química equivalente a $400 \mathrm{Kg} \mathrm{ha}^{-1}$ do formulado 04-14-08 (RAIJ et al. 1996) e o milho recebeu adubação química equivalente a $450 \mathrm{Kg} \mathrm{ha}^{-1}$ do formulado 08-28-16 (ALVES et al., 1999). Os vasos foram irrigados diariamente de forma a mantê-los com o substrato próximo a capacidade de campo.

A semeadura de ambas as espécies foi realizada no mesmo dia, distribuindo-se 10 sementes de soja e milho, em seus respectivos por vasos, na profundidade de até três centímetros e, após a emergência das plântulas realizou-se o desbaste, mantendo-se três plântulas de soja e milho, respectivamente.
Os herbicidas foram aplicados quando as plântulas de soja estavam no estádio fenológico V1, V2 e V3 (RITCHIE et al., 1982) respectivamente e, em plântulas de milho no estádio V3, utilizando-se um pulverizador costal pressurizado a $\mathrm{CO}_{2}$, com barra de pulverização com dois bicos, AD-IA 007 (Magnojet) espaçados de 0,50m entre si. A velocidade de deslocamento e a pressão $(310 \mathrm{kPa})$ foram ajustadas para obter um volume de aplicação de $65 \mathrm{~L} \mathrm{ha}^{-1}$.

A avaliação do controle das plantas de soja voluntária proporcionado pela combinação dos herbicidas (Tabela 1) foram realizadas aos 7 e 14 dias após a aplicação (DAA) por meio de uma escala percentual de notas, variando de 0 (zero) a $100 \%$, em que $0 \%$ representava a ausência de controle e $100 \%$ a morte de todas as plantas, sendo também correlacionadas com a escala de notas da Asociación Latino Americana de Malezas (ALAM, 1974), a qual varia de 1 (nenhum a pobre) a 6 (excelente controle) de acordo com a Tabela 2. Os aspectos utilizados para determinação das notas visuais de controle foram à quantidade e uniformidade das injúrias, aliada e quantidade de plantas mortas. Das cinco notas atribuídas ao controle das plantas de soja voluntária referentes às repetições de cada tratamento obteve-se a moda útil para reduzir a informação de um conjunto de dados qualitativos expressos sob a forma de nomes ou categorias (PIMENTEL GOMES, 2000).

Tabela 2. Escala de notas da ALAM (1974) utilizada para avaliação da porcentagem de controle da soja voluntária.

\begin{tabular}{ccc}
\hline Notas & Porcentagem de controle (\%) & Grau de controle \\
\hline 1 & $0-40$ & Nenhum a pobre \\
2 & $41-60$ & Regular \\
4 & $61-70$ & Suficiente \\
5 & $71-80$ & Bom \\
6 & $81-90$ & Muito Bom \\
\hline
\end{tabular}

As avaliações de fitotoxidade dos herbicidas nas plantas de milho foram realizadas aos 7,14 e 21 DAA, tomando-se por base a escala de notas da European Weed Research Council (EWRC) de 1964 (Tabela 3). Das cinco notas atribuídas à fitotoxidade nas plantas milho referente às repetições de cada tratamento também se obteve a moda útil para reduzir a informação de um conjunto de dados qualitativos expressos sob a forma de nomes ou categorias (PIMENTEL GOMES, 2000).
Após a última avaliação visual de fitotoxidade nas plantas de milho, aos 21 DAA, determinou-se o diâmetro e o comprimento médio de três plântulas de milho por repetição. O diâmetro do colmo foi obtido por meio de um paquímetro digital a um centímetro do substrato e o comprimento foi obtido utilizando-se uma régua graduada para medida da distância do colo até a última aurícula expandida. 
L. L. COSTA et al.

Tabela 3. Classificação da escala EWRC para fitotoxidade em plantas de milho.

\begin{tabular}{ccc}
\hline Índice & Fitotoxidade à planta \\
\hline 1 & Nula \\
2 & Muito leve \\
3 & Leve \\
4 & Moderada \\
5 & Média \\
6 & Quase forte \\
7 & Forte \\
8 & Muito forte \\
9 & Morte da planta \\
\hline
\end{tabular}

Foi quantificada a massa seca da raiz (MSR) e parte aérea das plantas (MSPR) de milho, aos 21 DAA. As plantas de cada vaso e de cada repetição foram cortadas rente ao substrato para determinação da massa seca da parte aérea. $\mathrm{O}$ substrato de cada vaso foi peneirado para separação das raízes de cada tratamento. A parte aérea e raízes das plantas foram acondicionadas em saco de papel, colocados em estufa de circulação forçada de ar a $60^{\circ} \mathrm{C}$, até atingirem peso constante. Posteriormente, as amostras foram pesadas para obtenção de massa seca de parte aérea e raiz.

Os dados obtidos, após confirmação dos pressupostos de normalidade do resíduo (Shapiro-wilk) e homogeneidade de variâncias (Cochran), foram submetidos ao teste $F$ da análise de variância e, quando significativo $(\mathrm{p}<0,01$ ou $\mathrm{p}<0,05$ ), as médias dos tratamentos foram comparadas pelo teste de Skott-Knott.

\section{Resultados e Discussão}

\section{Controle de soja voluntária}

Aos sete dias após a aplicação (DAA) dos herbicidas, com exceção do glyphosate (Roundup Transorb, 480 g e.a. L ${ }^{-1}$, SL, Monsanto) e da testemunha (sem aplicação de herbicida), as plantas de soja voluntária, nos estádios V1 e V2, verificou-se notas 4 e 5, respectivamente. (Tabela 4). Considerou-se nota 4 para as plantas com folhas amareladas, mas com alguma parte da planta ainda verde e nota 5 para as plantas de soja completamente amareladas, de acordo com escala visual de ALAM (1974).

Tabela 4. Efeito dos herbicidas no controle da soja voluntária RR, em estádio de desenvolvimento V1, V2 e V3 aos 7 e 14 dias após aplicação (DAA), tomando-se por base a escala visual da ALAM (1974).

\begin{tabular}{|c|c|c|c|c|c|c|c|}
\hline \multirow{2}{*}{\multicolumn{2}{|c|}{ Tratamentos }} & \multicolumn{2}{|c|}{ Soja V1 } & \multicolumn{2}{|c|}{ Soja V2 } & \multicolumn{2}{|c|}{ Soja V3 } \\
\hline & & \multicolumn{6}{|c|}{---- DAA ---- } \\
\hline Ingrediente ativo & Dose (e.a e i.a. kg ha ${ }^{-1}$ ) & 7 & 14 & 7 & 14 & 7 & 14 \\
\hline${ }^{1}$ Glyphosate $+{ }^{2}$ Atrazine & $0,960+2,4$ & 4 & 6 & 5 & 6 & 6 & 6 \\
\hline${ }^{1}$ Glyphosate $+{ }^{2}$ Atrazine & $0,960+1,2$ & 4 & 6 & 5 & 6 & 6 & 6 \\
\hline${ }^{1}$ Glyphosate $+{ }^{3}$ Atrazine & $0,960+2,4$ & 4 & 6 & 5 & 6 & 6 & 6 \\
\hline${ }^{1}$ Glyphosate $+{ }^{3}$ Atrazine & $0,960+1,2$ & 4 & 6 & 5 & 6 & 5 & 6 \\
\hline${ }^{2}$ Atrazine & 2,4 & 4 & 6 & 5 & 6 & 6 & 6 \\
\hline${ }^{2}$ Atrazine & 1,2 & 4 & 6 & 5 & 6 & 6 & 6 \\
\hline${ }^{3}$ Atrazine & 2,4 & 4 & 6 & 5 & 6 & 6 & 6 \\
\hline${ }^{3}$ Atrazine & 1,2 & 4 & 6 & 5 & 6 & 5 & 6 \\
\hline${ }^{1}$ Glyphosate & 0,960 & 1 & 1 & 1 & 1 & 1 & 1 \\
\hline Testemunha & -------- & 1 & 1 & 1 & 1 & 1 & 1 \\
\hline
\end{tabular}

${ }^{1}$ (Roundup Transorb, 480 g e.a. L ${ }^{-1}$, SL, Monsanto); ${ }^{2}$ (Primóleo, $400 \mathrm{~g}$ i.a L ${ }^{-1}$, SC, Syngenta); ${ }^{3}$ (Proof ,500 g i.a L L SC). Escala visual da ALAM (1974): nota 1 - 0 a $40 \%$ de controle; nota 2 - 41 a $60 \%$ de controle; nota $3-61$ a $70 \%$ de controle; nota 4 - 71 a $80 \%$ de controle; nota 5 - 81 a $90 \%$ de controle; e, nota 6 - 91 a $100 \%$ de controle. 
Na soja em estádio V3, aos sete DAA, os tratamentos com glyphosate (Roundup Transorb, 480 g e.a. $\mathrm{L}^{-1}$, SL, Monsanto) em mistura com o herbicida atrazine (Proof, 500 g i.a L ${ }^{-1}, \mathrm{SC}$, Syngenta) ou somente o herbicida atrazine $\left(\right.$ Proof $\left.^{\circledR}\right)$, ambos com a menor dose, receberam nota 5, ou seja, verificou-se controle muito bom da soja voluntária (Tabela 4). Entretanto, chama-se a atenção que, os demais tratamentos já com 7 DAA causaram a morte das plantas (Tabela 4).

O controle de plantas voluntárias de soja em estádio V3 foi mais rápido em relação aos estádios V1 e V2 (Tabela 4). Esse resultado não era esperado, visto que, de acordo com Lima et al. (2011) quanto mais avançado o estádio de desenvolvimento, mais tolerantes as plantas se tornam à ação dos herbicidas. Supõe-se que esse resultado seja decorrente da maior absorção dos produtos pelas plantas de soja em estádio V3 devido ao seu maior índice de área foliar em relação aos estádios V1 e V2. Além disso, os produtos com o herbicida atrazine apresentam ação de contato quando aplicados via foliar (SUMMERS, 1980) e proporcionaram possivelmente mais rápida visualização dos sintomas, devido a esse maior índice de área foliar das plantas.

Aos 14 DAA constatou-se $100 \%$ de controle das plantas voluntárias de soja RR, nos estádios V1, V2 e V3, nos tratamentos associados aos produtos formulados com o herbicida atrazine, sendo, portanto, uma alternativa para o controle da soja RR (Tabela 4). Resultados similares ao deste estudo foram encontrados por Dan et al. (2011), os quais concluíram que a atrazine foi eficiente no controle de plantas voluntárias de soja, variedade Valiosa $\mathrm{RR}^{\circledR}$, em estádio fenológico V3. Em trabalho mais recente, Grigolli et al. (2017) constataram que doses crescentes de atrazine proporcionaram controle da soja voluntária e não houve efeito negativo na produtividade do milho.

No tratamento com aplicação do glyphosate não houve controle da soja voluntária, comprovando a tolerância que a soja RR possui em relação a esse herbicida (Tabela 4). De acordo com Bradshaw et al. (1997), a soja geneticamente modificada é imune aos efeitos destrutivos e letais do glyphosate. Entretanto, Zobiole et al. (2010) relata que em algumas cultivares de soja pode ocorrer o amarelecimento das folhas após a aplicação do glyphosate, originando o sintoma denominado de "yellow flashing", esse sintoma não foi observado no presente estudo quando aplicado somente o glyphosate.

A associação de glyphosate e atrazine é comum no manejo de plantas daninhas no milho, principalmente em condições de segunda safra. Entretanto, a mistura do glyphosate e atrazine ou uso somente da atrazine proporcionaram controle semelhante das plantas voluntárias de soja (Tabela 4). Desta forma, recomenda-se a mistura dos referidos herbicidas somente quando houver outras plantasdaninhas de folha estreita (monocotiledôneas) sensíveis ao glyphosate na área.

Cabe salientar que, o uso da maior dose de atrazine dentro da recomendação de bula dos produtos formulados Primóleo (400 g i.a L L $\mathrm{L}^{-1}$, SC, Syngenta) e Proof (500 g i.a L ${ }^{-1}$, SC, Syngenta) proporcionaram controle semelhante das plantas de soja em relação às menores doses dos respectivos herbicidas (Tabela 4). Desta forma, o uso da menor dose de atrazine $1,2 \mathrm{~g}$ i.a. ha ${ }^{-1}$, tanto por meio do Primóleo ${ }^{\circledR}$ quanto por meio do Proof ${ }^{\circledR}$, é interessante tanto do ponto de vista ecológico como econômico para manejar plantas de soja voluntária RR, na cultura do milho.

\section{Seletividade dos herbicidas às plantas de milho}

O herbicida atrazine (Primóleo, 400 g i.a L ${ }^{-1}, \mathrm{SC}$, Syngenta), aos sete dias após a aplicação (DAA), na dose de 2,4 kg i.a. ha ${ }^{-1}$ isolado ou associado ao glyphosate (Roundup Transorb, $480 \mathrm{~g}$ e.a. $\mathrm{L}^{-1}$, SL, Monsanto) foram os únicos tratamentos que causaram uma leve intoxicação no milho (Tabela 5), observada por uma clorose na tonalidade verde claro (amarelecimento) das folhas em relação à testemunha, isto provavelmente devido ter ocorrido penetração seguido de absorção da atrazine. Entretanto, os sintomas foram temporários e com o desenvolvimento, aos $21 \mathrm{DAA}$, as plantas de milho estavam com a coloração normal (Tabela 5).

De modo geral, pela análise visual de fitotoxidade, as plantas de milho não tiveram comprometimento aparente pelo uso dos herbicidas (Tabela 5). Resultados similares foram encontrados por López-Ovejero et al. (2003), Trezzi et al. (2005) e Adegas et al. (2011) ao estudar a seletividade de herbicidas na cultura do milho. Os autores verificaram que atrazine aplicado isoladamente ou com algumas misturas não causaram toxicidade ao milho ou ela foi muito baixa. 
L. L. COSTA et al.

Tabela 5. Avaliação visual de fitotoxidade dos herbicidas em plantas de milho realizada aos 7,14 e 21 dias após aplicação (DAA), tomandose por base a escala de notas EWRC (1964).

\begin{tabular}{|c|c|c|c|c|}
\hline \multirow{2}{*}{ Ingredientes ativo } & \multirow{2}{*}{$\begin{array}{c}\text { Dose } \\
\text { (e.a e i.a. } \mathrm{kg} \mathrm{ha}^{-1} \text { ) }\end{array}$} & \multicolumn{3}{|c|}{ Fitotoxidade } \\
\hline & & 7 DAA & 14 DAA & 21 DAA \\
\hline${ }^{1}$ Glyphosate $+{ }^{2}$ Atrazine & $0,960+2,4$ & 3 & 3 & 1 \\
\hline${ }^{1}$ Glyphosate $+{ }^{2}$ Atrazine & $0,960+1,2$ & 2 & 2 & 1 \\
\hline${ }^{1}$ Glyphosate $+{ }^{3}$ Atrazine & $0,960+2,4$ & 1 & 2 & 2 \\
\hline${ }^{1}$ Glyphosate $+{ }^{3}$ Atrazine & $0,960+1,2$ & 1 & 1 & 2 \\
\hline${ }^{2}$ Atrazine & 2,4 & 3 & 2 & 1 \\
\hline${ }^{2}$ Atrazine & 1,2 & 2 & 2 & 2 \\
\hline${ }^{3}$ Atrazine & 2,4 & 1 & 1 & 2 \\
\hline${ }^{3}$ Atrazine & 1,2 & 1 & 1 & 1 \\
\hline${ }^{1}$ Glyphosate & 0,960 & 1 & 1 & 1 \\
\hline Testemunha & -------- & 1 & 1 & 1 \\
\hline
\end{tabular}

${ }^{1}$ (Roundup Transorb, 480 g e.a. L ${ }^{-1}$, SL, Monsanto); ${ }^{2}$ (Primóleo, 400 g i.a L ${ }^{-1}$, SC, Syngenta); ${ }^{3}$ (Proof ,500 g i.a $\left.\mathrm{L}^{-1}, \mathrm{SC}\right)$.. Classificação de fitotoxidade da EWRC (1964): nota 1 - Nula; nota 2 - Muito leve; nota 3 - Leve; nota 4 - Moderada; nota 5 - Média; nota 6 - Quase forte; nota 7 - Forte; nota 8 - Muito forte; e, nota 9 - Morte da planta.

Ao analisar o efeito dos herbicidas sobre as outras variáveis, observou-se que o herbicida atrazine (Primóleo, 400 g i.a L L ${ }^{-1}$ SC, Syngenta), nas doses de 1,2 e $2,4 \mathrm{~kg}$ i.a. ha ${ }^{-1}$, associado ao glyphosate (Roundup Transorb, 480 g e.a. $\mathrm{L}^{-1}$, SL, Monsanto) ou isolado e o herbicida atrazine (Proof, $500 \mathrm{~g}$ i.a L ${ }^{-1}, \mathrm{SC}$, Syngenta) na dose de $2,4 \mathrm{~kg}$ i.a. ha $\mathrm{ha}^{-1}$, proporcionaram menor crescimento e diâmetro de colmo das plantas de milho comparado com os demais tratamentos e a testemunha (Tabela 6), sem, contudo haver diferença significativa entre os tratamentos para massa seca de raiz e de parte aérea das plantas de milho (Tabela 6).

$\mathrm{O}$ herbicida atrazine (Proof, $500 \mathrm{~g}$ i.a. $\mathrm{L}^{-1}$, SC, Syngenta) na dose de 1,2 kg i.a. ha ${ }^{-1}$ ou nas doses de $1,2 \mathrm{~kg}$ i.a. $\mathrm{ha}^{-1}$ e 2,4 kg i.a. ha ${ }^{-1}$ associado ao glyphosate não diferiram da testemunha para as variáveis comprimento médio das plantas, diâmetro de colmo, massa seca de raiz e parte aérea (Tabela 6). No controle de soja voluntária no cultivo de milho, os resultados evidenciam a possibilidade de maior segurança no uso da atrazine (Proof, $500 \mathrm{~g}^{\mathrm{i} . \mathrm{a} \mathrm{L}} \mathrm{L}^{-1}$, SC, Syngenta) do que o uso da atrazine (Primóleo, 400 g i.a L ${ }^{-1}$, SC, Syngenta).

A aplicação do glyphosate isolado ou associado à atrazine nas duas formulações comerciais, Primóleo ${ }^{\circledR}$ ou Proof $^{\circledR}$ proporcionaram às plantas de milho maior massa seca de raiz e massa seca de parte aérea, em torno de $26 \%$ e $37 \%$, respectivamente, superior à testemunha (Tabela 6). Assim, presume-se, o glyphosate poderá proporcionar efeito no desenvolvimento das plantas de milho tolerante ao glyphosate (Tabela 6), conhecido como efeito hormese, entretanto são necessárias outras pesquisas para se comprovar esta pressuposição na cultura do milho tolerante ao glyphosate conforme já evidenciado em outras culturas anuais, semiperenes e perenes não tolerantes ao glyphosate (SILVA et al., 2009; SILVA et al., 2012; PEREIRA et al., 2013; NASCENTES et al., 2017, BRITO et al. 2018). 
L. L. COSTA et al.

Tabela 6. Comprimento médio de plantas (CMP) ( $\mathrm{cm})$, diâmetro médio de colmo (DMC) (mm), massa seca de raiz (MSR) (g planta $\left.{ }^{-1}\right)$ e massa seca da parte aérea (MSA) $\left(\mathrm{g}_{\text { planta }}{ }^{-1}\right)$ de plantas de milho aos 21 dias após a aplicação dos tratamentos herbicidas.

\begin{tabular}{cccccc}
\hline Ingrediente ativo & Dose & CMP & DMC & MSR & MSA \\
\cline { 3 - 6 } & $\left(\right.$ e.a e i.a. kg ha $\left.{ }^{-1}\right)$ & $(\mathrm{cm})$ & $(\mathrm{mm})$ & $\left(\mathrm{g} \mathrm{planta}^{-1}\right)$ & $\left(\mathrm{g} \mathrm{planta}^{-1}\right)$ \\
\hline${ }^{1}$ Glyphosate $+{ }^{2}$ Atrazine & $0,960+2,4$ & $13,52 \mathrm{~b}$ & $8,27 \mathrm{~b}$ & $9,27 \mathrm{a}$ & $12,99 \mathrm{a}$ \\
${ }^{1}$ Glyphosate $+{ }^{2}$ Atrazine & $0,960+1,2$ & $15,50 \mathrm{~b}$ & $8,28 \mathrm{~b}$ & $9,08 \mathrm{a}$ & $15,48 \mathrm{a}$ \\
${ }^{1}$ Glyphosate $+{ }^{3}$ Atrazine & $0,960+2,4$ & $16,84 \mathrm{a}$ & $9,42 \mathrm{a}$ & $9,09 \mathrm{a}$ & $15,10 \mathrm{a}$ \\
${ }^{1}$ Glyphosate $+{ }^{3}$ Atrazine & $0,960+1,2$ & $15,87 \mathrm{a}$ & $9,40 \mathrm{a}$ & $9,51 \mathrm{a}$ & $12,77 \mathrm{a}$ \\
${ }^{2}$ Atrazine & 2,4 & $14,20 \mathrm{~b}$ & $7,77 \mathrm{~b}$ & $7,65 \mathrm{a}$ & $10,87 \mathrm{a}$ \\
${ }^{2}$ Atrazine & 1,2 & $11,88 \mathrm{~b}$ & $7,73 \mathrm{~b}$ & $7,44 \mathrm{a}$ & $11,42 \mathrm{a}$ \\
${ }^{3}$ Atrazine & 2,4 & $12,40 \mathrm{~b}$ & $8,24 \mathrm{~b}$ & $8,16 \mathrm{a}$ & $10,29 \mathrm{a}$ \\
${ }^{3}$ Atrazine & 1,2 & $15,60 \mathrm{a}$ & $8,99 \mathrm{a}$ & $8,22 \mathrm{a}$ & $11,87 \mathrm{a}$ \\
${ }^{1}$ Glyphosate & 0,960 & $17,34 \mathrm{a}$ & $9,88 \mathrm{a}$ & $9,57 \mathrm{a}$ & $15,10 \mathrm{a}$ \\
${ }^{\text {Testemunha }}$ & $-1,-----$ & $15,02 \mathrm{a}$ & $9,58 \mathrm{a}$ & $7,57 \mathrm{a}$ & $11,00 \mathrm{a}$ \\
\hline
\end{tabular}

A mistura de glyphosate e atrazine, em ambas as formulações, proporcionou controle da soja voluntária RR nos estádios de desenvolvimento V1, V2 e V3 (Tabela 4) e desenvolvimento do milho compatível com a testemunha (Tabela 6). Com isso, é possível associar com segurança, em uma única operação, o controle de soja voluntária e manejo de plantas daninhas em pós-colheita no milho.

\section{Conclusões}

Quando o objetivo for apenas o controle da soja voluntária RR dispensa-se a adição do glyphosate na calda com atrazine. Ambas as doses de atrazine contida nos dois produtos comerciais controlam eficientemente as plantas de soja voluntária RR na cultura do milho.

Há seletividade na cultura do milho com o herbicida atrazine $\left(\right.$ Primóleo $^{\circledR}$ ou Proof ${ }^{\circledR}$ ) aplicado isolado ou em mistura com o glyphosate considerando o acúmulo de massa seca de raiz e parte aérea.

\section{Referências}

Adegas, F.S.; Voll, E.; Gazziero, D.L.P. Manejo de plantas daninhas em milho safrinha em cultivo solteiro ou consorciado à braquiária ruziziensis. Pesquisa Agropecuária Brasileira, v.46, n.10, p.1226-1233, 2011.

Alves, V.M.C.; Vasconcellos, C.A.; Freire, F.M.; Pitta, G.V.E.; França, G.E.; Rodrigues Filho, A.; Araújo, J.M.; Vieira, J.R.; Loureiro, J.E. Milho. In: Comissão de fertilidade do solo do estado de Minas Gerais.
Recomendações para o uso de corretivos e fertilizantes em Minas Gerais: $5^{a}$ aproximação. Viçosa, 1999. p. 314316 .

Artuzi, J.P.; Contiero, R.L. Herbicidas aplicados na soja e produtividade do milho em sucessão. Pesquisa Agropecuária Brasileira, v.41, n.7, p.1119 $\square$ 1123, 2006.

Asociación Latino Americana de Malezas - ALAM. Recomendaciones sobre unificación de los sistemas de evaluación en ensayos de control de malezas, v.1, n.1, p.35-38, 1974.

Bradshaw, L.; Padgette, S.; Kimball, S.; Wells, B. Perspectives on Glyphosate resistance. Weed Technology, v.11, n.1, p.189-198, 1997.

BRASIL. MAPA. Instrução Normativa $\mathrm{N}^{\circ} 40$, de 11 de outubro de 2018. Diário Oficial da República Federativa do Brasil. Brasília, seção1, n. 198, p.3, 2018.

Brito, I.P.F.S.; Tropaldi, L.; Carbonari, Caio A.; Velini, E.D. Hormetic effects of glyphosate on plants. Pest Management Science, v. 74, n.5, p. 1064-1070, 2018.

Costa, N.V.; Zobiole, L.H.S.; Scariot, C.A.; Pereira, G.R.; Moratelli, G. Glyphosate tolerant volunteer corn control at two development stages. Planta Daninha, v.32, n.4, p.675$682,2014$.

Dan, H.A.; Procópio, S.O.; Barroso, A.L.L.; Dan, L.G.M.; Oliveira Neto, A.M.; Guerra, N. Controle de plantas voluntárias de soja com herbicidas utilizados em milho. 
Revista Brasileira de Ciências Agrárias, v.6, n.2, p.253257, 2011.

European Weed Research Council. Report of the 3rd and 4th meetings of EWRC. Comittee of methods in Weed Research. Weed Research, v.4, p.88, 1964.

Gazziero, D.L.P. Misturas de agrotóxicos em tanques nas propriedades agrícolas do brasil. Planta Daninha, v.33, n.1, p.83-92, 2015.

Grigolli, J.F.J.; Gitti, D.C.; Lourenção, A.L.F. Controle de plantas de soja e supressão do capim em milho consorciado com Brachiaria ruziziensis. Arquivos do Instituto Biológico, v. 84, n.1, p.1-7, 2017.

Ikeda, F.S. Resistência de plantas daninhas em soja resistente ao glyphosate. Informe Agropecuário, v.34, n.276, p. 1-8, 2013.

Lima, D.B.C.; Da Silva, A.G.; Procópio, S.O.; Barroso, A.L.L.; Dan, H.A. Controle químico de plantas voluntárias de soja Roudup Ready ${ }^{\circledR}$ em diferentes estádios de desenvolvimento. Revista Caatinga, v.24, n.3, p.64-70, 2011.

López-Ovejero, R.F.; Fancelli, A.L.; Dourado Neto, D.; García y García, A.; Christoffoleti, P.J. Seletividade de herbicidas para a cultura de milho (Zea mays) aplicados em diferentes estádios fenológicos da cultura. Planta Daninha, v.21, n.3, p.413-419, 2003.

Maciel, C.D.G.; Zobiole, L.H.S.; Souza, J.I.; Hirooka, E.; Lima, L.G.N.V.; Soares, C.R.B.; Pivatto, R.A.D.; Fuchs, G.M.; Helvig, E.O. Eficácia do herbicida Haloxyfop R (GR142) isolado e associado ao 2,4-D no controle de híbridos de milho $\mathrm{RR}^{\circledR}$ voluntário. Revista Brasileira de Herbicidas, v.12, n.2, p.112-123, 2013.

Marca, V.; Procópio, S.O.; Silva, A.G. da; Volf, M. Chemical control of glyphosate $\square$ resistant volunteer maize. Revista Brasileira de Herbicidas, v.14, n.2, p.103 $\square 110$, 2015.

Petter, A.F.; Segate, D.; Almeida, F.A.; Neto, F.A.; Pacheco, L.P. Incompatibilidade física de misturas entre inseticidas e fungicidas. Comunicata Scientiae, v. 4, n. 2, p. 129-138, 2013.

Petter, F.A.; Sima, V.M.; FraportI, M.B.; Pereira, C.S.; Procópio, S.O.; Silva, A.F. Volunteer RR $^{\circledR}$ corn management in roundup ready ${ }^{\circledR}$ soybean - corn succession system. Planta Daninha, v.33, n.1, p.119 $\square 128,2015$.

Pereira, F.C.M.; Nepomuceno, M.; Pires, R.N.; Parreira, M.C.; ALVES, P.L.C.A. Response of Eucalyptus ( $E$. urograndis) at different doses of glyphosate. Journal of Agricultural Science, v. 5, n.1, p. 66-74, 2013.

Pimentel Gomes, F. Curso de estatística experimental. 14. ed. Piracicaba: Degaspari, 2000. 477 p.

Queiroz, A.A.; Martins, J.A.S.; Cunha, J.P.A.R. Adjuvantes e qualidade da água na aplicação de agrotóxicos. Bioscience Journal, v.24, n.4, p.8-19, 2008.

Raij, B. van; Cantarella, H.; Quaggio, J.A.; Furlani, A.M.C. (Ed.). Recomendações de adubação e calagem para o Estado de São Paulo. 2. ed. Campinas: Instituto Agronômico \& Fundação IAC, 1996. 285 p.

Nascentes R.F, Carbonari, C.A., Simões, P.S., Brunelli, M.C., Velini, E.D. e Duke, S.O. Low doses of glyphosate enhance growth, $\mathrm{CO}_{2}$ assimilation, stomatal conductance and transpiration in sugarcane and eucalyptus. Pest Management Science, v. 74, n. 5, p.1197-1205, 2017.

Ritchie, S.; Hanway, J.J.; Thompson, H.E. How a soybean plant develops. Ames: Iowa State University of Science and Technology, 1982.

Santos, H.G.; Jacomine, P.K.T.; Anjos, L.H.C.; Oliveira, V.A.; Lumbreras, J.F.; Coelho, M. R; Almeida, J. A.; Cunha, T. J. F.; Oliveira, J. B. Latossolos. In:

Sistema Brasileiro de Classificação de Solos. 4. ed. Brasília :Brasília: Embrapa, 2014., Cap. 10 p. 171 - 194.

Silva, J. C.; Arf, O.; Gerlach, G.A.; Kuriyama, C.S. ; Rodrigues, R.A.F . Efeito hormese de glyphosate em feijoeiro. Pesquisa Agropecuaria Tropical, v. 42, n. 3, p. 295-302, 2012.

Silva, M.A; Aragão, N.C.; Barbosa, M.A.; Jeronimo E.M.; Carlin, S.D. Efeito hormótico de gliphosate no desenvolvimento inicial de cana-de-açúcar. Bragantia, v. 68, n.4, p.973-978, 2009.

Summers, L. A. The Bipyridinium Herbicides. Academy Press: New York. 1980. 449p.

Trezzi, M.M.; Felippi, C.L.; Nunes, A.L.; Carnieleto, C.E.; Ferreira, A.R.J. Eficácia de controle de plantas daninhas e toxicidade ao milho da mistura de foramsulfuron $\mathrm{e}$ iodosulfuron isoladamente ou em associação com atrazine e/ ou clorpirifós. Planta Daninha, v.23, n.4, p.653-659, 2005.

Zobiole, L.H.S.; Oliveira Júnior, R.S.; Kremer, R.J.; Muniz, A.S.; Oliveira Júnior, A. Nutrient accumulation and photosynthesis in glyphosate resistant soybeans is reduced under glyphosate use. Journal Plant Nutrition, v.33, n.1214, p.1860-1873, 2010. 